\title{
Aerial Image Segmentation with Clustering Using Fireworks Algorithm
}

\author{
Muhammad Hariz Arasy ${ }^{1}$, Suyanto ${ }^{2}$, Kurniawan Nur Ramadhani ${ }^{3}$ \\ School of Computing, Telkom University \\ Jl. Telekomunikasi Terusan Buah Batu, Bandung, West Java 40257, Indonesia \\ ${ }^{1}$ harizmhd@student.telkomuniversity.ac.id, ${ }^{2}$ suyanto@telkomuniversity.ac.id, ${ }^{3}$ kurniawannr@telkomuniversity.ac.id
}

\begin{abstract}
As an improved method of the standard Fireworks Algorithm, which is one of the swarm intelligence methods, the Adaptive Fireworks Algorithm (AFWA) can be exploited to optimize any cluster-based segmentation method. In this paper, AFWA is applied to perform aerial image segmentation and its performance is then compared to K-means. Since aerial imagery has different data characteristics when compared to other types of images, the segmentation quality is assessed systematically using special benchmarks. Two evaluation metrics are used here. First, Probabilistic Rand Index (PRI). Second, Variation of Information (VI). The experimental results show that AFWA produces better segmentation qualities than K-means.
\end{abstract}

Keywords: Image segmentation, aerial image, clustering, adaptive fireworks algorithm.

\begin{abstract}
Abstrak
Sebagai perbaikan dari Algoritma Fireworks standar, yang merupakan salah satu metode swarm intelligence, Adaptive Fireworks Algorithm (AFWA) dapat dimanfaatkan untuk mengoptimasi metode segmentasi berbasis klaster. Pada makalah ini, AFWA diterapkan untuk melakukan segmentasi gambar udara dan selanjutnya kinerjanya dibandingkan dengan $\mathrm{K}$ means. Berhubung pencitraan udara memiliki karakteristik data yang berbeda dibanding jenis gambar lain, maka kualitas segmentasi dinilai secara sistematis menggunakan alat ukur khusus. Di sini digunakan dua metrik evaluasi. Pertama, Probabilistic Rand Index (PRI). Kedua, Variation of Information (VI). Hasil percobaan menunjukkan bahwa AFWA menghasilkan kualitas segmentasi yang lebih baik daripada K-means.
\end{abstract}

Kata Kunci: Segmentasi citra, citra udara, clustering, adaptive fireworks algorithm.

\section{Pendahuluan}

C ITRA udara dan citra satelit merupakan jenis citra digital yang digunakan pada remote sensing. Perbedaan mendasar yang dimiliki citra udara jika dibandingkan dengan citra satelit adalah proses pemotretannya yang dilakukan dibawah ketinggian awan sehingga menghasilkan citra yang lebih detail dan kompleks. Sebuah citra udara dapat menyediakan data yang digunakan dalam pengambilan keputusan pada pengendalian bencana alam, pengembangan wilayah kota, dan pemantauan lingkungan. Untuk mendapatkan data ini, informasi pada citra udara harus terlebih dahulu diekstrak menjadi format yang dapat dibaca oleh sistem penganalisis citra. Proses ekstraksi ini dikenal dengan proses segmentasi citra. Pada proses segmentasi, citra dipartisi ke dalam region (bagian-bagian) yang berbeda. Setiap region harus se-homogen mungkin dan sekaligus harus berbeda antar satu sama lain.

Secara garis besar, metode-metode segmentasi citra dapat dikategorikan ke dalam metode berbasis edge detection, thresholding, clustering, dan region merging [2]. Tidak semua metode ini bekerja dengan baik pada citra udara. Metode berbasis edge detection dan metode berbasis thresholding lebih efektif jika digunakan pada citra sederhana yang memiliki objek dengan latar belakang yang kontras [12]. Sementara itu, metode berbasis region merging digunakan secara luas oleh komunitas remote sensing. Hanya saja, 
kelemahan metode berbasis region merging adalah dibutuhkannya bantuan user dalam menentukan titik awal region. Akibatnya, kualitas hasil segmentasi menjadi sangat bergantung pada pemahaman user terkait citra yang disegmentasi. Di sisi lain, metode berbasis clustering memberikan hasil yang secara keseluruhan cukup baik pada berbagai macam jenis citra [12], baik itu citra natural, citra sintetik, maupun citra udara. Metode yang umum digunakan secara luas adalah K-means Clustering [4]. Metode ini bekerja sangat cepat. Tetapi, kualitas segmentasi sangat bergantung pada jumlah cluster yang ditentukan oleh user. Dalam menentukan jumlah cluster, diperlukan pemahaman yang mendalam terhadap data yang hendak dikelompokkan. Tapi untungnya, pada bidang segmentasi citra telah diusulkan metode untuk menentukan jumlah cluster secara otomatis [9].

\section{A. Latar Belakang}

Fireworks Algorithm (FWA) merupakan salah satu algoritma metaheuristic yang menggunakan konsep Swarm Intelligence (SI). Sebuah sistem SI memanfaatkan sejumlah simple agents berkecerdasan sederhana yang kemudian saling berinteraksi dengan satu sama lain untuk menyelesaikan suatu tugas yang kompleks. Algoritma SI biasa digunakan sebagai alternatif dari algoritma non-heuristic dalam menyelesaikan permasalahan clustering dan optimization. Sejak diperkenalkan tahun 2010 [10], FWA telah dikembangkan secara signifikan menjadi dua variasi, yaitu: Enhanced FWA [14] dan Adaptive FWA [3]. Berdasarkan hasil dari [10], FWA terbukti memiliki kecepatan konvergensi dan akurasi solusi global yang lebih unggul dibandingkan algoritma SI lainnya.

\section{B. Masalah dan Batasan}

Algoritma EFWA dan AFWA belum pernah digunakan untuk melakukan segmentasi citra. FWA di sisi lain, sudah pernah digunakan untuk segmentasi dengan metode berbasis thresholding [11] dan metode berbasis clustering [6]. Pada kedua penelitian, segmentasi dilakukan pada sejumlah citra grayscale yang sebagian besar merupakan citra natural dan citra sintetik. Dengan kata lain, FWA belum pernah digunakan untuk proses segmentasi yang berfokus pada citra udara. Selain itu, kedua penelitian membuktikan bahwa FWA dapat memberikan kualitas yang sebanding dengan algoritma state-of-art dari SI. Kualitas FWA telah dinilai berdasarkan kemampuannya dalam mengoptimasi fungsi objektif pada [11] dan dalam mengoptimasi kepadatan dan keterpisahan antar cluster pada [6]. Hanya saja, bagaimana hasil segmentasi FWA dapat memenuhi kebutuhan dari proses analisis citra, belum dibahas pada kedua penelitian.

\section{Solusi yang Diusulkan}

Pada penelitian ini, AFWA diimplementasikan untuk melakukan segmentasi pada citra udara. AFWA dipilih ketimbang FWA dan EFWA karena memiliki performansi yang lebih baik serta merupakan perbaikan dari kedua algoritma tersebut. Kualitas hasil segmentasinya kemudian dinilai secara sistematis dengan menggunakan benchmark yang khusus untuk mengevaluasi segmentasi citra udara. Agar dapat melakukan segmentasi citra, AFWA dapat diimplementasikan sebagai alternatif dari algoritma K-means dalam mengoptimasi proses clustering pada metode segmentasi berbasis clustering. Teknik clustering dipilih selain karena sudah pernah diaplikasikan pada FWA dasar, juga karena lebih sesuai untuk citra udara dibandingkan dengan metode berbasis thresholding.

Tujuan dari penelitian ini adalah untuk mengevaluasi AFWA dalam melakukan segmentasi citra udara. Kinerja AFWA dibandingkan dengan kinerja K-means berdasarkan kualitas hasil clustering dan kualitas hasil segmentasi. K-means digunakan sebagai pembanding karena merupakan versi non-heuristic dari metode segmentasi yang digunakan AFWA pada penelitian ini. Dengan membandingkan kedua metode, seberapa besar kemajuan yang diberikan oleh AFWA dapat diukur dengan jelas.

\section{Organisasi Penulisan}

Pada bagian 2 akan diulas secara ringkas mengenai clustering, konsep dasar dan perkembangan FWA hingga AFWA, dan benchmark yang digunakan pada penelitian ini. Pada bagian 3 akan dijelaskan mengenai metode segmentasi yang diusulkan. Kemudian pada bagian 4 akan dipaparkan hasil eksperimen dan evaluasi. Terakhir, pada bagian 5 disampaikan kesimpulan. 


\section{TinjauAn Pustaka}

\section{A. Clustering}

Konsep dasar dari clustering adalah menemukan kesamaan antar data dan mengelompokkannya ke dalam satu kelompok. Proses pengelompokkan ini dilakukan dengan cara memaksimalkan kesamaan data di dalam kelompok dan meminimalkan kesamaan data antar kelompok [2]. Tingkat kesamaan ini dapat diukur menggunakan pengukuran jarak Euclidean, Cosine, Jaccard, dll.

Algoritma clustering yang umum digunakan adalah K-means [4]. Algoritma ini membagi sebanyak $n$ data ke dalam $k$ kelompok melalui serangkaian proses yang iteratif. Algoritma ini memiliki dua fase pada setiap iterasi-nya, yakni fase assignment dan fase update. Sebelum kedua fase ini dimulai, $k$ centroid ditempatkan pada ruang data terlebih dahulu. Pada fase assignment setiap data dikelompokkan dengan centroid yang memiliki mean terdekat. Kemudian pada fase update, algoritma menghitung means dari tiap kelompok untuk menentukan centroid baru. Kedua fase ini terus diiterasi hingga fungsi kriteria mencapai nilai minimum [7].

\section{B. Adaptive Fireworks Algorithm}

FWA merupakan salah satu algoritma yang menggunakan konsep SI. Ciri khas dari algoritma SI adalah terdapatnya simple agents berkecerdasan sederhana yang saling berinteraksi dengan satu sama lain untuk mencapai suatu tujuan. Dalam proses pencarian solusi, simple agents pada sistem FWA menggunakan teknik eksplorasi dan eksploitasi yang terinspirasi oleh peristiwa ledakan kembang api [10]. Percikan api yang dihasilkan oleh ledakan kembang api dapat dipandang sebagai sebuah proses pencarian di sekitar titik tertentu. Posisi di mana kembang api akan meledak, dianggap sebagai suatu individu yang dinamakan fireworks atau seed. Di sekitaran individu tersebut akan bermunculan beberapa individu baru yang dinamakan sparks (percikan). Sparks terbaik pada setiap ledakan, akan menjadi fireworks pada ledakan berikutnya. Ledakan akan terus dihasilkan hingga suatu individu mengenai atau cukup dekat dengan titik solusi yang dicari.

Pada FWA, amplitudo setiap fireworks (yang merupakan satu faktor penting) dihitung berdasarkan perbedaan fitness antara fireworks tersebut dengan individu terbaik (yang fireworks atau sparks). Perhitungan ini menyebabkan ukuran amplitudo dari fireworks terbaik akan selalu bernilai 0 dan tidak terlalu memberikan kontribusi yang signifikan terhadap proses pencarian secara keseluruhan.

Untuk mengatasi permasalahan tersebut, pada EFWA [14] dilakukan pengecekan amplitudo setiap fireworks. Dengan menggunakan fungsi penurunan non-linear sebagai ambang batas minimal, amplitudo fireworks terbaik dijamin tidak akan bernilai 0 dan juga akan terus berkurang seiring meningkatnya iterasi. Penurunan amplitudo ini dilakukan guna mensimulasikan ruang pencarian yang semakin sempit seiring dengan semakin dekatnya solusi. Akan tetapi, fungsi penurunan ini sering kali tidak cocok dengan fungsi objektif. Pada fungsi objektif tertentu, amplitudo dapat berkurang terlalu cepat sehingga menyebabkan algoritma mencapai konvergensi sebelum waktunya. Sebaliknya, jika amplitudo berkurang terlalu lambat, ruang pencarian menjadi terlalu luas untuk dapat menemukan solusi yang persis.

AFWA [3] diusulkan oleh Li et al. untuk memperbaiki EFWA. Pada AFWA, digunakan sebuah metode adaptif yang menghitung amplitudo fireworks terbaik dengan menggunakan informasi yang didapat dari iterasi sebelumnya. Awalnya, pada iterasi pertama, amplitudo terbaik diatur sesuai jarak maksimum dari ruang pencarian. Kemudian pada akhir setiap iterasi, dipilih satu individu (fireworks atau sparks) dengan fitness yang lebih buruk sekaligus memiliki jarak paling dekat dengan fireworks terbaik. Jarak ini kemudian dijadikan sebagai amplitudo dari fireworks terbaik pada iterasi berikutnya. Metode ini akan menghasilkan amplitudo adaptif yang memiliki peran penting dalam mengendalikan skala pencarian agar sesuai dengan fase pencarian yang sedang dijalani. Sehingga diharapkan algoritma dapat beralih dari fase pencarian global ke fase pencarian lokal dengan laju yang tepat.

\section{ASD Benchmark}

Aerial image Segmentation Data set (ASD) [13] berisi 80 citra udara beresolusi tinggi berukuran $512 \times 512$ piksel. Data set terdiri dari berbagai macam obyek, di antaranya sekolah, perumahan, kota, gudang dan pembangkit listrik. ASD juga menyediakan ground-truth yang terdiri dari hasil segmentasi 
yang dibuat oleh 4 orang subyek manusia. Ground-truth dapat digunakan sebagai benchmark untuk mengukur kualitas dari hasil segmentasi mesin. Pengukuran dilakukan dengan membandingkan hasil segmentasi mesin terhadap ground-truth dengan menggunakan metrik evaluasi. Nilai yang didapatkan dari hasil perhitungan metrik evaluasi, dapat merepresentasikan tingkat kemiripan antara hasil segmentasi mesin dan ground-truth. Dua metrik evaluasi yang digunakan oleh ASD Benchmark yang juga digunakan pada penelitian ini adalah PRI dan VI.

1) Probabilistic Rand Index: PRI awalnya diperkenalkan sebagai metode untuk mengevaluasi hasil clustering [8]. Cara kerja metrik ini adalah dengan membandingkan kecocokan antara sepasang data di dalam cluster. Indeks Rand dari hasil segmentasi $S$ dan ground-truth $G$ dihitung dari jumlah pasangan piksel yang memiliki label yang sama di $S$ dan $G$ serta pasangan dengan label yang berbeda di kedua segmentasi, akan dibagi dengan jumlah total pasangan piksel yang ada. Jika diketahui terdapat beberapa ground-truth pada himpunan $G_{k}$, maka PRI didefinisikan sebagai

$$
\operatorname{PRI}\left(S, G_{k}\right)=\frac{1}{T} \sum_{i<j}\left[c_{i j} p_{i j}+\left(1-c_{i j}\right)\left(1-p_{i j}\right)\right],
$$

di mana $c_{i j}$ adalah kejadian ketika piksel $i$ dan $j$ memiliki label yang sama, $p_{i j}$ menyatakan probabilitasnya, dan $T$ adalah jumlah total pasangan piksel yang ada [8]. Semakin besar nilai PRI, maka dapat dinyatakan bahwa kecocokan antara kedua segmentasi semakin tinggi.

2) Variation of Information: Metrik VI diperkenalkan sebagai metode untuk melakukan perbandingan clustering [5]. Metrik ini mengukur jarak antara dua segmentasi dalam hal rata-rata entropi kondisional dari kedua segmentasi. VI dari hasil segmentasi $S$ dan ground-truth $G$ didefinisikan sebagai

$$
V I(S, G)=H(S)+H(G)-2 I(S, G),
$$

di mana $H$ dan $I$ masing-masing menyatakan entropi dan kesamaan informasi antara hasil segmentasi $S$ dan ground-truth $G$ [5]. Jika beberapa ground-truth digunakan, maka diambil rata-rata dari seluruh hasil evaluasi ground-truth [1]. Semakin kecil nilai VI, maka dapat dinyatakan bahwa kesamaan informasi antara kedua segmentasi semakin tinggi.

\section{Segmentasi Citra MEngGunAKan AFWA}

Pada metode $K$-means Clustering, segmentasi citra dilakukan dengan cara mengelompokkan pikselpiksel ke dalam cluster yang memiliki kesamaan fitur, seperti tingkat kecerahan, warna, pola tekstur, dan lokasi spasial. Piksel dikelompokkan dengan centroid (titik pusat) yang memiliki tingkat kemiripan fitur atau jarak terdekat. Disini, AFWA dapat digunakan untuk mengoptimasi peletakkan centroid dengan menggunakan fungsi objektif yang mengukur tingkat kemiripan centroid terhadap anggota cluster-nya.

Kebanyakan citra udara yang ada pada data set ASD memiliki region dengan tingkat kecerahan yang berbeda-beda. Contohnya sebuah bangunan dapat memiliki sekaligus bagian terang dan gelap pada bagian atapnya. Hal ini menyebabkan kesalahan segmentasi jika pengelompokkan yang dilakukan adalah berdasarkan tingkat kecerahan. Untuk itu, clustering pada K-means dan AFWA dilakukan berdasarkan warna.

Pada Gambar 1, dijabarkan langkah-langkah yang perlu dilalui dalam melakukan segmentasi suatu citra udara menggunakan AFWA. Secara garis besar, langkah-langkah tersebut dapat dikelompokkan menjadi tiga tahapan utama, yakni tahapan preprocessing, clustering, dan output.

\section{A. Preprocessing}

Masalah yang ditemukan pada citra ASD adalah noise (kebisingan gambar). Citra yang dipenuhi bagianbagian kecil yang tidak berarti dapat menyebabkan kesalahan segmentasi. Untuk itu digunakan filter bilateral pada citra udara. Filter ini dipilih karena dapat mengurangi noise sambil tetap mempertahankan garis tepi pada citra. 


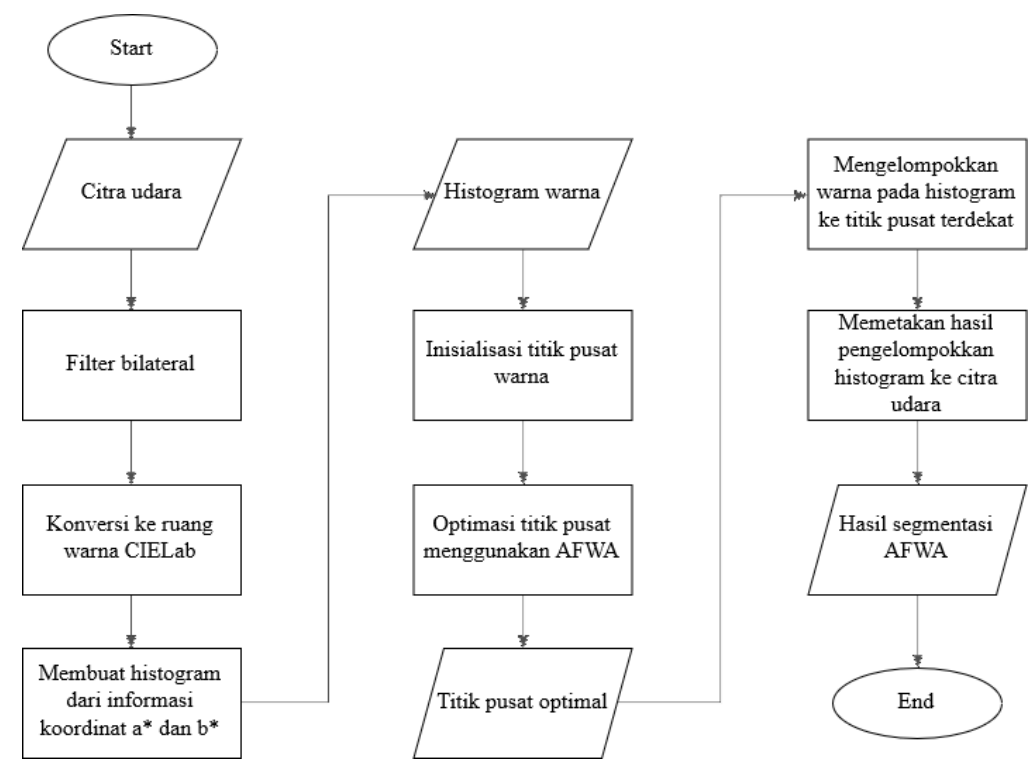

Gambar 1: Alur segmentasi citra udara menggunakan AFWA

Setelah penerapan filter, agar dapat dilakukan pengelompokkan warna, citra udara terlebih dahulu diubah kedalam ruang warna CIELab. Koordinat $\mathrm{L}^{*}$ pada CIELab menyatakan nilai lightness (tingkat kecerahan) pada suatu piksel, sedangkan koordinat $\mathrm{a}^{*}$ dan $\mathrm{b}^{*}$ menyatakan nilai warna. Agar lightness tidak mempengaruhi hasil segmentasi, koordinat $\mathrm{L}^{*}$ tidak perlu dipersiapkan untuk proses clustering. Selanjutnya, dibuatkan histogram yang menyatakan distribusi nilai koordinat $\mathrm{a}^{*}$ dan $\mathrm{b}^{*}$. Clustering warna dilakukan dengan mengelompokkan data pada histogram. Hal ini dilakukan untuk efisiensi waktu, mengingat banyaknya piksel pada citra yang memiliki warna yang sama.

\section{B. AFWA Clustering}

Dalam melakukan proses clustering, warna-warna pada citra dikelompokkan berdasarkan jarak warna tersebut terhadap centroid warna. Suatu individu pada sistem optimasi AFWA dapat merepresentasikan vektor koordinat a* dan $\mathrm{b}^{*}$ dari $N_{c}$ centroid. Vektor tersebut terbangun sebagai berikut:

$$
x_{i}=\left(m_{i 1 a^{*}}, \ldots, m_{i j a^{*}}, \ldots, m_{i N c a^{*}}, m_{i 1 b^{*}}, \ldots, m_{i j b^{*}}, \ldots, m_{i N c b^{*}}\right)
$$

di mana $x_{i}$ menyatakan individu ke- $i$ dari sistem optimasi AFWA, $m_{i j a^{*}}$ merupakan koordinat a* dari centroid ke- $j$ milik individu ke- $i$, dan $m_{i j b^{*}}$ merupakan koordinat $\mathrm{b}^{*}$ dari centroid ke- $j$ milik individu ke$i$. Centroid yang didapatkan dari suatu individu, digunakan untuk mengelompokkan histogram citra. Setiap warna pada histogram dikelompokkan dengan centroid terdekat berdasarkan jarak squared euclidean:

$$
d\left(z_{p}, m_{j}\right)=\left(z_{p a *}-m_{j a *}\right)^{2}+\left(z_{p b *}-m_{j b *}\right)^{2}
$$

di mana $z_{p a *}$ menyatakan data histogram ke- $p$ pada koordinat a* dan $m_{j a *}$ menyatakan koordinat a* dari centroid ke- $j$. Hasilnya berupa cluster warna yang kualitasnya dapat diukur menggunakan Quantization Error $(Q E)$ sebagai berikut:

$$
Q E=\frac{\sum_{j=1}^{N_{c}}\left[\sum_{\forall Z_{p} \in C_{i j}} d\left(z_{p}, m_{j}\right) /\left|C_{i j}\right|\right]}{N_{c}}
$$

di mana $\left|C_{i j}\right|$ menyatakan jumlah data yang dikelompokkan pada cluster ke- $j$ dari individu ke- $i$. Selanjutnya nilai fitness didapat dari fungsi objektif:

$$
\text { fitness }=1 / Q E
$$


di mana nilai fitness terbaik adalah nilai terbesar. Mengingat tujuan AFWA adalah menemukan vektor koordinat centroid yang menghasilkan cluster dengan fitness terbaik, maka AFWA diatur agar dapat memaksimasi fungsi objektif. Rangkuman dari proses pengevaluasian centroid dari suatu individu $x_{i}$ mulai dari ekstraksi centroid hingga didapatkan nilai $Q E$ dan fitness-nya dapat dilihat pada Algoritma 1.
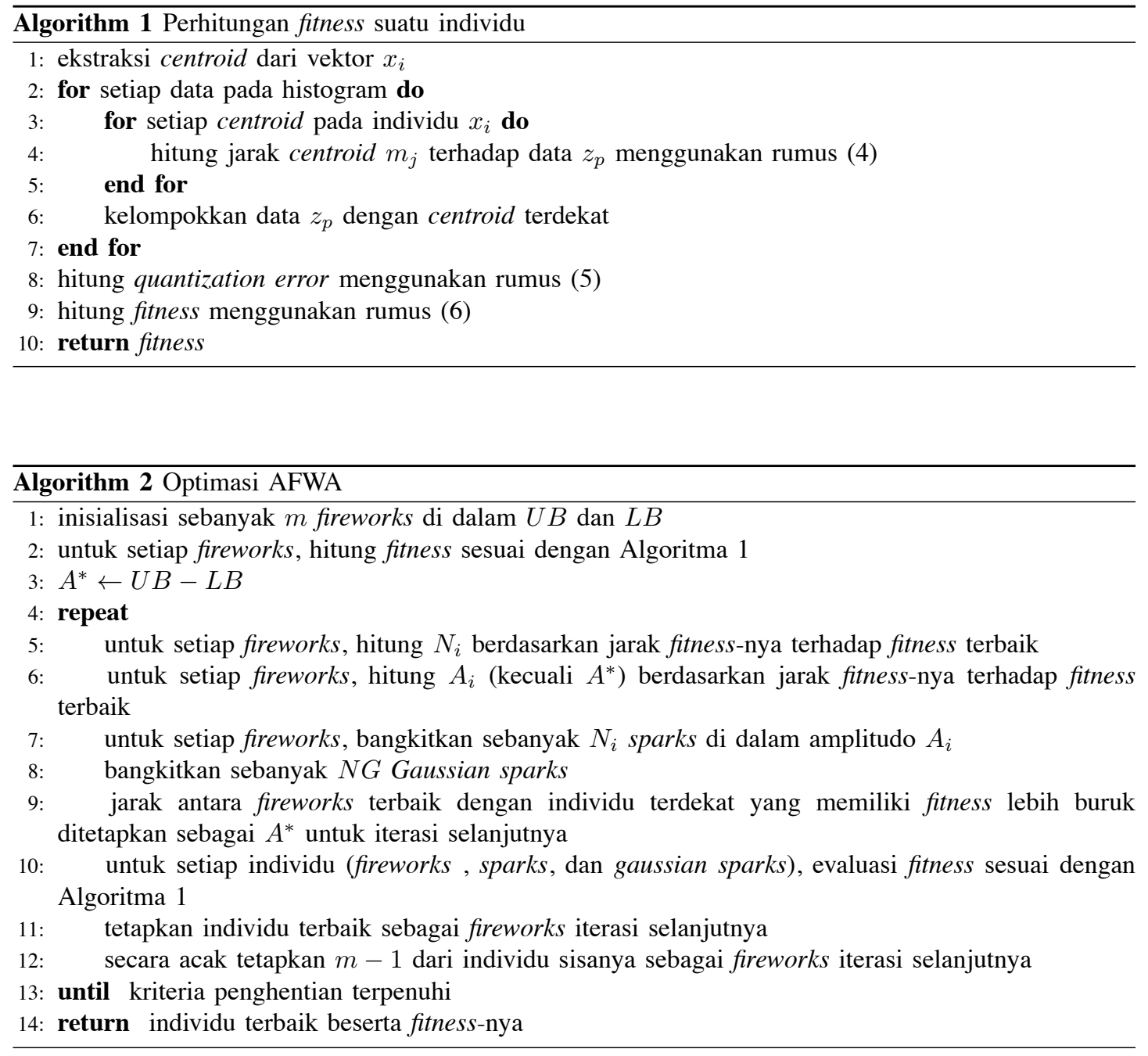

Proses optimasi AFWA mulai dari proses inisialisasi centroid hingga didapatkan centroid dengan fitness terbaik dijelaskan oleh Algoritma 2. Dengan $m$ menyatakan jumlah dari fireworks, $U B$ dan $L B$ menyatakan batas atas dan batas bawah, $A_{i}$ merupakan amplitudo dari fireworks ke- $i, N_{i}$ menyatakan jumlah sparks dari fireworks ke- $i$, dan $A^{*}$ merupakan amplitudo dari fireworks terbaik. Pada proses inisialisasi fireworks, batas atas dan batas bawah menyesuaikan nilai tertinggi dan terendah pada histogram warna.

\section{Output}

Dari individu dengan fitness terbaik, maka didapat centroid yang digunakan untuk mengelompokkan histogram warna untuk terakhir kalinya. Hasil clustering dari histogram warna ini digunakan untuk memetakan label pada citra udara. Setelah setiap warna pada citra udara diberi label sesuai dengan indeks cluster-nya. Akhirnya, citra udara yang telah berlabel di-output-kan sebagai hasil segmentasi. 
Tabel I: Perhitungan Quantization Error tehadap hasil clustering K-means dan AFWA

\begin{tabular}{|l|l|l|}
\hline \multirow{2}{*}{} & \multicolumn{2}{|c|}{ QE } \\
\cline { 2 - 3 } & ODS & OIS \\
\hline K-means & 8.588 & 8.667 \\
AFWA & 6.878 & 6.754 \\
\hline
\end{tabular}

Tabel II: Metrik evaluasi terhadap hasil segmentasi K-means dan AFWA

\begin{tabular}{|l|c|c|c|c|}
\hline \multirow{2}{*}{} & \multicolumn{2}{|c|}{ PRI } & \multicolumn{2}{c|}{ VI } \\
\cline { 2 - 5 } & ODS & OIS & ODS & OIS \\
\hline Human & 0.826 & 0.838 & 1.049 & 1.002 \\
\hline K-means & 0.469 & 0.474 & 3.134 & 3.119 \\
AFWA & 0.487 & 0.492 & 2.953 & 2.951 \\
\hline
\end{tabular}

\section{HASIL DAN DISKUSI}

Metode segmentasi K-means clustering digunakan sebagai pembanding dasar terhadap metode segmentasi AFWA clustering. Kedua algoritma dijalankan pada data set ASD hingga didapatkan hasil segmentasi berupa citra berlabel. Dua aspek yang dinilai dari kedua metode adalah kualitas hasil clustering dan kualitas hasil segmentasi. Dalam membandingkan kualitas hasil segmentasi, digunakan benchmark framework yang disediakan oleh data set. Benchmark ini bekerja dengan cara mengukur perbandingan antara segmentasi yang dihasilkan mesin dan segmentasi hasil buatan manusia dengan menggunakan metrik evaluasi. Pada penelitian ini, hasil segmentasi AFWA dan hasil segmentasi K-means diukur tingkat kemiripannya terhadap ground-truth dengan menggunakan perhitungan metrik PRI dan VI. Selanjutnya, untuk menilai kualitas hasil clustering, tingkat kerapatan cluster yang dihasilkan masing-masing algoritma diukur dengan membandingkan rata-rata Quantization Error.

Berhubung kedua metode segmentasi berbasis clustering, maka hasil segmentasi yang dikeluarkan bergantung pada jumlah centroid/cluster yang dipilih. Berdasarkan cara pemilihan skala (jumlah centroid), terdapat dua kemungkinan percobaan. Pertama, optimal data set scale (ODS), yang digunakan ketika jumlah centroid yang dipilih merupakan jumlah centroid yang dianggap sebagai skala yang paling optimal untuk keseluruhan citra di data set. Kedua, optimal image scale (OIS) [1], yang digunakan ketika jumlah centroid yang dipilih merupakan jumlah centroid yang dianggap paling optimal untuk citra tersebut.

Pada Tabel I ditampilkan hasil perhitungan Quantization Error dari hasil clustering AFWA dan Kmeans dalam pemilihan skala ODS dan OIS. Selanjutnya, Tabel II menunjukkan hasil evaluasi metrik PRI dan VI dari hasil segmentasi AFWA dan K-means menggunakan pemilihan skala ODS dan OIS. Nilai yang ditampilkan pada kedua tabel merupakan nilai rata-rata dari seluruh data set. Selain itu, pada Tabel II juga dicantumkan nilai PRI dan VI dari hasil segmentasi manusia. Nilai ini didapatkan dari perbandingan hasil segmentasi salah satu subyek manusia dengan hasil segmentasi subyek lainnya dengan menggunakan metrik evaluasi PRI dan VI. Hasilnya, nilai yang didapatkan merupakan nilai yang dapat merepresentasikan kualitas dari hasil segmentasi manusia.

Pada Tabel I dapat diamati bahwa hasil clustering AFWA memiliki nilai Quantization Error yang lebih rendah dibandingkan K-means. Dengan kata lain, cluster yang dihasilkan AFWA lebih padat dibanding K-means. Hasil ini menjukkan AFWA mampu menghasilkan cluster lebih baik dibanding K-means.

Citra udara yang biasanya dipenuhi oleh objek kecil yang tidak berarti, dapat menyebabkan kekeliruan dalam proses clustering dan menghasilkan region yang oversegmented (tersegmentasi secara berlebihan). Hal ini merupakan tantangan terbesar yang dihadapi oleh metode segmentasi berbasis clustering. Hasil segmentasi AFWA dan K-means terhadap enam citra udara dari data set dapat dilihat pada Gambar 2 di mana setiap region diwarnai secara acak. Secara kasat mata dapat diperhatikan bahwa secara keseluruhan hasil AFWA memiliki jumlah region yang lebih sedikit dibandingkan hasil K-means. Hal ini membuktikan bahwa AFWA mampu mengurangi masalah oversegmentation. Akan tetapi, Oversegmentation masih ditemukan pada citra yang memiliki banyak objek kecil tidak berarti (seperti citra pada kanan atas) dan bagian citra dengan tekstur yang tidak teratur (seperti pada citra kiri bawah).

Pada Tabel II dapat diamati bahwa hasil segmentasi AFWA secara konsisten lebih unggul dibandingkan K-means pada setiap metrik evaluasi. Berdasarkan metrik PRI, AFWA unggul dengan selisih 0.018 pada ODS dan OIS. Kemudian berdasarkan metrik VI, AFWA unggul dengan selisih 0.181 pada ODS dan 

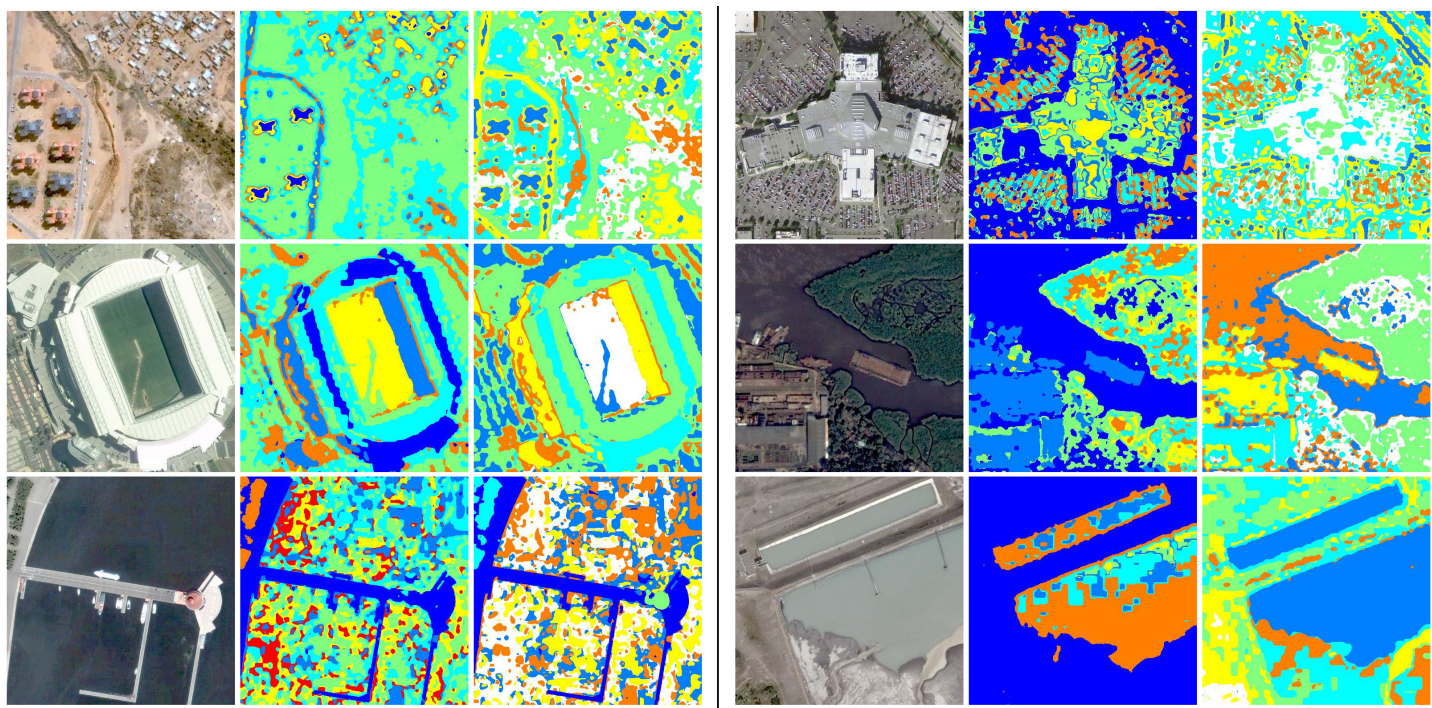

Gambar 2: Hasil segmentasi dari 6 citra udara pada Aerial image Segmentation Data set. Dari kiri ke kanan: citra udara, hasil segmentasi AFWA clustering, hasil segmentasi K-means clustering.

0.168 pada OIS. Akan tetapi, jika dibandingkan dengan kualitas segmentasi manusia, AFWA masih jauh tertinggal. Berdasarkan metrik PRI, AFWA masih tertinggal dengan selisih 0.339 pada ODS dan 0.351 pada OIS. Berdasarkan metrik VI, AFWA masih tertinggal dengan selisih 1.904 pada ODS dan 1.949 pada OIS. Memang sudah bisa diprediksi bahwa kemampuan segmentasi mesin masih jauh tertinggal dari kemampuan segmentasi manusia. Akan tetapi, dengan membandingkan kedua hasil segmentasi, kita dapat mengukur seberapa besar kontribusi AFWA dalam mencapai kemampuan segmentasi yang mendekati kemampuan manusia.

\section{KESIMPULAN}

Pada penelitian ini telah dipaparkan teknik clustering menggunakan AFWA dan mengaplikasikannya untuk segmentasi citra udara. Berdasarkan metrik evaluasi PRI dan VI, metode AFWA secara keseluruhan menghasilkan kualitas segmentasi yang lebih baik dibanding K-means dan lebih mendekati hasil segmentasi manusia, walaupun belum cukup signifikan. Hasil segmentasi ini masih dapat ditingkatkan dengan cara memperhitungkan informasi lain pada proses clustering, seperti koordinat ruang dan pola tekstur pada citra. Selain itu, FWA dan versi modifikasinya juga sangat berpotensi untuk dikembangkan pada metode segmentasi berbasis edge detection, thresholding, dan region merging.

\section{ACKNOWLEDGMENT}

Kami mengucapkan terima kasih sebesar-besarnya kepada seluruh teman dan rekan kerja di Universitas Telkom, khususnya di Fakultas Informatika, atas segala dukungannya dalam penyelesaian riset dan penulisan makalah ini.

[1] P. Arbelaez, M. Maire, C. Fowlkes, and J. Malik. Contour detection and hierarchical image segmentation. IEEE Transactions on Pattern Analysis and Machine Intelligence, 33(5):898-916, May 2011. 
[2] S. Chebbout and H. F. Merouani. Comparative study of clustering based colour image segmentation techniques. In 2012 Eighth International Conference on Signal Image Technology and Internet Based Systems, pages 839-844, Nov 2012.

[3] J. Li, S. Zheng, and Y. Tan. Adaptive fireworks algorithm. In 2014 IEEE Congress on Evolutionary Computation (CEC), pages 3214-3221, July 2014.

[4] J. Macqueen. Some methods for classification and analysis of multivariate observations. In In 5-th Berkeley Symposium on Mathematical Statistics and Probability, pages 281-297, 1967.

[5] Marina Meilă. Comparing clusterings: An axiomatic view. In Proceedings of the 22Nd International Conference on Machine Learning, ICML '05, pages 577-584, New York, NY, USA, 2005. ACM.

[6] Priya Ranjan Misra and Tapas Si. Image segmentation using clustering with fireworks algorithm. In 2017 11th International Conference on Intelligent Systems and Control (ISCO), pages 97-102. IEEE, 2017.

[7] S. Na, L. Xumin, and G. Yong. Research on k-means clustering algorithm: An improved k-means clustering algorithm. In 2010 Third International Symposium on Intelligent Information Technology and Security Informatics, pages 63-67, April 2010.

[8] William M. Rand. Objective criteria for the evaluation of clustering methods. Journal of the American Statistical Association, 66(336):846-850, 1971.

[9] Siddheswar Ray and Rose H Turi. Determination of number of clusters in k-means clustering and application in colour image segmentation. In Proceedings of the 4th international conference on advances in pattern recognition and digital techniques, pages 137-143. Calcutta, India, 1999.

[10] Ying Tan and Yuanchun Zhu. Fireworks Algorithm for Optimization, pages 355-364. Springer Berlin Heidelberg, Berlin, Heidelberg, 2010.

[11] Milan Tuba, Nebojsa Bacanin, and Adis Alihodzic. Multilevel image thresholding by fireworks algorithm. In 2015 25th International Conference Radioelektronika (RADIOELEKTRONIKA), pages 326-330. IEEE, 2015.

[12] S. S. Varshney, N. Rajpal, and R. Purwar. Comparative study of image segmentation techniques and object matching using segmentation. In 2009 Proceeding of International Conference on Methods and Models in Computer Science (ICM2CS), pages $1-6$, Dec 2009.

[13] J. Yuan, S. S. Gleason, and A. M. Cheriyadat. Systematic benchmarking of aerial image segmentation. IEEE Geoscience and Remote Sensing Letters, 10(6):1527-1531, Nov 2013.

[14] S. Zheng, A. Janecek, and Y. Tan. Enhanced fireworks algorithm. In 2013 IEEE Congress on Evolutionary Computation, pages 2069-2077, June 2013. 
